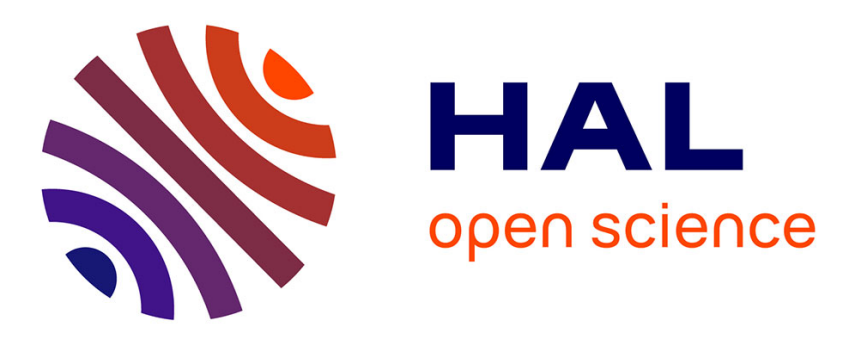

\title{
When efficient market hypothesis meets Hayek on information: beyond a methodological reading
}

\author{
Nathanaël Colin-Jaeger, Thomas Delcey
}

\section{To cite this version:}

Nathanaël Colin-Jaeger, Thomas Delcey. When efficient market hypothesis meets Hayek on information: beyond a methodological reading. Journal of Economic Methodology, 2020, 27 (2), pp.97-116. 10.1080/1350178X.2019.1675896 . hal-01933895

\section{HAL Id: hal-01933895 \\ https://hal.science/hal-01933895}

Submitted on 24 Nov 2018

HAL is a multi-disciplinary open access archive for the deposit and dissemination of scientific research documents, whether they are published or not. The documents may come from teaching and research institutions in France or abroad, or from public or private research centers.
L'archive ouverte pluridisciplinaire HAL, est destinée au dépôt et à la diffusion de documents scientifiques de niveau recherche, publiés ou non, émanant des établissements d'enseignement et de recherche français ou étrangers, des laboratoires publics ou privés. 


\title{
Beyond a Methodological Reading, When Fama Meets Hayek on
}

\author{
Information
}

\author{
Nathanael Colin ${ }^{1} \&$ Thomas Delcey ${ }^{2}$
}

\begin{abstract}
:
Hayek and Fama are sometimes seen as proposing a comparable theory of prices. Hayek proposes to understand prices as information conveyer from the process of competition, while Fama defines efficiency as the fact that all information in a market is integrated in assets prices. This close up ignores huge differences between the authors. This paper explains how a lineage between Hayek and the theory of informational efficiency of Fama can be illustrated while taking into account these differences. We introduce in order to defend this claim a distinction between methodology and epistemology: methodology is seen as the way an author operationalizes his broader conceptions whereas epistemology is defined as the core conception of his theory. We particularly emphasise a homogeneous shift in the epistemology of Hayek and the theory of efficiency. We conclude that this shift gives a content to what some authors called neoliberalism as a form of Weltanshauung.
\end{abstract}

Key words: Epistemology of Economics, Information, Efficient Market Hypothesis, Hayek, Fama, Price Theory, Neoliberalism.

\footnotetext{
${ }^{1}$ Ecole Normale Supérieur de Lyon, Triangle (UMR 5206), nathanael.Colin@ens-lyon.fr

${ }^{2}$ Centre d'Economie de la Sorbonne (UMR 8174), Université Paris Panthéon Sorbonne, thomas.delcey@univparis1.fr
} 


\section{Introduction}

Hayek is often seen as a founding father of neoliberalism (Dostaler, 2001; Mirowksi \& Plewhe, 2009; Dardot \& Laval, 2009; Audier, 2012; Burgin, 2012; and a lot more), that is to say a set of theories and practices heading toward the reduction of the role of the state and the promotion of competition throughout society. Some authors underline that Hayek introduced a shift in economics and politics with the introduction of the notion of information (Hirschleifer 1973; Grossman \& Stiglitz, 1976 and 1980; Mirowski 2009a, 2009b; Vivès, 2008, 2014), and draw a comparison with other theories, especially informational efficiency theory in finance, developed mainly by Fama, following Working, who uses information in order to define efficiency. This comparison appears to be of the utmost importance since finance is one of the main elements defining neoliberalism (Fourcade-Gourinchas \& Babb, 2002; Krippner, 2005; Lévy \& Duménil, 2014; Cahill \& Konings, 2017). Hence the goal of the comparison is to highlight a common Weltanschauung (Mirowski, 2009b, p. 112) or World Reason (Dardot \& Laval, 2009; Cahill \& Konings, 2017; Konings, 2018), namely a common representation of the world, especially of the market and its role, between Hayek and Fama. According to these authors this common representation of the world stems from the introduction of the concept of information, that Hayek borrowed to cybernetics (Mirowski, 2002), and that transformed the concepts of market and competition, opening in doing so a new conception of economics.

The comparison is at first sight relevant: the concept of information is central in the works of Hayek, Working and Fama, where information is the set of all relevant data for the action of individuals. Fama and Hayek use the system of prices as the way to centralize information while there can be no planification of centralization by an individual. It could 
then be said that the theory of efficiency formulated by Fama (1965a,b, 1970), when prices incorporate all the relevant information, is a restatement of the theory of price we can find in the work of Hayek. One may also point out the similarities in terms of consequences: both authors defend the deregulation of the market. But are those elements enough to justify the comparison and its theoretical outcomes?

While this intention appears considerable in its consequences little attention has been paid to the testing of this intuition. Most comparisons remain superficial, non-systematic or under developed. For example, Vivès (2008, p. 2), in his classical book on information and learning in markets, just asserts that:

Hayek's ideas are the basis for the rational expectations models that explain how rational agents make optimal inferences from prices, and other public statistics, about the relevant parameters about which they are uncertain.

But this sort of assimilation appears problematic. One difficulty differentiates itself frankly: Hayek, as a systematic author, developed a particular social philosophy and philosophy of economics. How can we compare him with authors who do not have the same range of analysis and a different methodology? It is well accepted now that a lot of similarities between Hayek and other authors, for example authors from the Chicago School, are mostly 
superficial (Butos, 1985, 1997; Hoover, 1988; Van Zijp, 1990; Mougeot, 2009), considering the particularity of Hayek's position as a representative of the Austrian tradition, which highly differs from the position of the American school, which is Fama's school. ${ }^{3}$ Some authors on this subject even wrote about two different paradigms (Audier, 2013), highlighting the very particular position of Hayek in the economic field, particularly on questions of methodology.

Our aim in this paper is to develop the comparison between the Hayekian theory and the development of efficiency in finance through the works of Working and Fama in order to justify the lineage between these authors while taking into consideration their important differences. The concept of information, initially called knowledge in the work of Hayek, will be the central theme of our analysis. We will then introduce an original distinction between methodology and epistemology in order to solve what we call the problem of comparisons. Our work does not claim to be totally historically accurate: we will compare analytically Hayek with Fama and Working assuming the coherence of authors throughout time - which is highly debatable for scholars, see Caldwell (2004) for instance. This main focus on analytical matters to the detriment of historical acuity calls for further investigations.

The thesis of this article is thus to show how bridges can be built between the Hayekian theory of information and the concept of information that we find in the works of Fama and Working on strong analytic basis. We then acknowledge the literature that stresses

\footnotetext{
${ }^{3}$ We use these distinctions between schools following other scholars, such as Caré (2016), that provided a typology of schools in economics.
} 
the importance of the effective differences between Hayek and other corpuses, but we will try to show that the similarities we can find are hidden beyond methodological differences, often not noticed by the authors defending the continuity between Hayek and Fama. Indeed, these authors share the same conception of information, broader than the scientific knowledge, which leads them to an identical conception of market and competition. This involves, as we will showcase, a formulation of efficiency that can be compared between Hayek and Fama. While the lineage between Hayek and Fama is sometimes taken as a self-evident fact in the literature, or criticized because the authors do not share enough in terms in methodology, we will show that this opposition can be overcome with a proper analysis of what these theories share analytically.

The first section will be dedicated to a reconstruction of Hayek's philosophy in two subsections. The first one will highlight the importance of the concept of information as a core concept in Hayek's philosophy. We will then underline the consequences of this starting point, namely a new conception of market and competition. The second section will develop the positions of Working and Fama. The sub-section on Working will concentrate on his theory of information and the symmetry he introduces between the observer and the observed, while the sub-section on Fama will pay particular attention to the formulation and efficiency and the transformation of the concepts of market and competition that stem from this starting point. In a third section we will defend our comparison between the two corpuses with a distinction between epistemology and methodology, epistemology consisting in the core 
concepts of the theory and methodology in the ways of operationalization. We will then provide four examples in order to illustrate and justify this distinction.

\section{Hayek, the Introduction of Information as a Core Concept:}

We will focus mainly on the work of Friedrich Hayek in this section. He is rightly acknowledged as one of the masterminds of the liberal and economic thought and has a great influence both theoretically and organizationally (Dostaler 2001; Mirowski \& Plewhe, 2009). Hayek distinguishes himself in many ways from the economic mainstream (Dostaler 2001; Caldwell 2004; Mirowski 2007; Caré 2016), the neoclassical theory, which is represented when he writes by the general equilibrium program, even though it is not fully developed until 1954 and the works of Arrow and Debreu. But it is highly debatable to say that his work did not have a decisive influence on the productions and the theoretical mutations of the discipline. Thus, Robert Lucas explicitly represented himself as a continuator of Hayek (Laidler, 1982, ix), regarding the status given to the concept of information for example.

However, there are some evidence for the differences between Hayekian views and others (Hoover, 1988), for example the Hayekian criticisms of the general equilibrium models (Hayek, 1948, 41). Our thesis consists in showing that beyond these differences there is, 
between Hayek and the efficiency theorists, a common ground based on the same problematic of knowledge and information.

Hayek is then interesting because he develops in a systematic way a subjectivist epistemology based upon the statement of the division of knowledge, which implies some major modifications for the understanding of concept such as market, competition and prices, relatively to the conception which Hayek sees as hegemonic in economics, the general equilibrium analysis and its theory of pure and perfect competition (Hayek, 1948). The concept of information appears central in this perspective because it is the starting point of Hayek theory. This introduction by Hayek of the concept of information, especially in the text of 1944, that is to say, "The Use of Knowledge in Society", will leave a mark on the whole discipline of economics, being one of the top 20 articles with the most citations of the American Economic Review.

We will use the terms knowledge and information as synonyms here, following Hayek himself and the habit taken by translators to translate knowledge by information:

I confess it took me a long time from my first breakthrough, in my essay « Economics and Knowledge » through the recognition of «Competition as a discovery Procedure » and my essay on «The pretence of Knowledge » to state my theory of the dispersal of 
information, from which follows my conclusions about the superiority of spontaneous formations to central direction (quoted in Mirowski \& Nik-Khah 2017, 66).

In the following sections we will use both words indifferently.

\section{A Knowledge Economics}

Hayek's theory is based upon a subjectivist position regarding knowledge (Hayek, 1952, 31), correlative to his individualism that we can sum up in the following way: there are only individuals, and they are the only entity that can be said to possess knowledge. This position is well developed in Individualism and Economic order (1948) and in The CounterRevolution of Science (1952). Hayek's subjectivism is more developed than the one we traditionally find in marginalism for the theory of value or in the Austrian perspective, for example in Menger position during the Methodenstreit or in Bohm-Bawerk's work on the interest rates, but found the social and economic order on the sole actions of the individuals. Birner (2006) distinguishes between four connected meanings of subjectivism: the facts of the social sciences are the opinions and desires of the agents (i), knowledge is divided and heterogenous (ii), knowledge is limited and local, and thus human reason must concede to the wisdom incorporated in the social rules (iii) and the fact that the agents and the theorists can 
understand the actions of other people only because their mind work in the same manner (iv).

All of these meanings stem from his position in theoretical psychology. Hayek (1979, 199200) underlines the importance of his book Sensory Order for his philosophy of social sciences and his theory of knowledge. In order to understand Hayek's views one as to start with this thesis, we will then see that his whole theory can be reconstructed from there (Birner, 2006; Butos, 1997).

The logical question of the coordination emerges from this position; this is the starting point of Hayek's analysis. This starting point is essential to identify since it has been called "the Hayek problem" by some scholars (Van Zjip 1990). How can we reconcile the fact that my knowledge is subjective with the subjective knowledge of others, and thus how a world made of individuals following their own interest based on their local knowledge can be in order? In order to understand Hayek, we have to present his thesis of the division of knowledge that clarifies this question. Some scholars consider that this thesis introduces a shift in Hayek's scientific production (Hutchison 1981; Butos 1985; Caldwell 1984, 1988). If the main discovery of Adam Smith is the division of labor, illustrated with the example of the fabric of pin in the beginning of the Wealth of Nations, the great discovery of Hayek in economics is the division of knowledge, that is to say the fact that knowledge is shared among the different members of society and cannot be centralized by one particular entity or person. Economics is then just not the realm of material exchanges but of cognitive exchanges too. It is remarkable here to underline the fact that Hayek develops this theory in the context of the 
controversy on the scientific possibility of economic planning led by Mises with his book Der Sozialismus written in 1922 from an article of 1920, which constitutes the background of these theoretical analyses. Hayek defines his problem in the following way:

The problem which we pretend to solve is how the spontaneous interaction of a number of people, each possessing only bits of knowledge, brings about a state of affairs in which prices correspond to costs, etc., and which could be brought about by deliberate direction only by somebody who possessed the combined knowledge of all those individuals. Experience shows us that something of this sort does happen, since the empirical observation that prices do tend to correspond to costs was the beginning of our science. But in our analysis, instead of showing what bits of information the different persons must possess in order to bring about that result, we fall in effect back on the assumption that everybody knows everything and so evade any real solution of the problem. (Hayek [ 1948, $50-51)$.

Or, with another formulation by Hayek:

How can the combination of fragments of knowledge existing in different minds bring about results which, if they were to be brought about deliberately, would require 
knowledge on the part of the directing mind which no single person can possess? (Hayek [ 1937] 1948, 54).

Knowledge in this frame refers as well to the present and future knowledge of prices, but also to the use that any individual can make of any goods they possess. This type of knowledge, or information, is not only the scientific knowledge but also all relevant information for the agents: how to use something, the quantities, and all the specific information given in a time and place. It is not only the knowledge of "what" but also the knowledge of "how". This information is then said non-homogenous because it cannot be reduced to one type of knowledge, for example the scientific knowledge. Information can then be anything useful for the individuals. It is for Hayek even more important than the scientific knowledge in order to understand the possibility of social coordination because most individuals rely primary on this wider type of knowledge for their actions. Here we can underline that the definition of information is very large and vague and can actually include almost everything, from the scientific knowledge available at a certain time to the very specific transformation of contexts and immediate circumstances, namely everything that can be useful for action. 
The starting point of Hayek is thus the fact that every individual possesses information, beliefs and desires that are his own. The major consequence is that nobody can know it all, because the information is for the main part subjective. The division of knowledge is then a starting point in order to explain economic and political phenomena, and not an element to explain, an explanans and not an explanandum. Agents are then cognitively limited, and this is why they follow social rules, or behavioural norms, that civilization created in order to promote cooperation. Here is a notable difference between Hayek and other economists: the rationality is always bounded socially for Hayek.

The situation on the market is then for Hayek a situation of cognitive fragmentation: everyone possesses information but it is impossible to centralize all the information, especially in an intentional mechanism of regulation. The individuals do what they can in order to fulfil their goals, using information they possess. The original division of knowledge introduces a clear rupture with the neoclassical model: the problem is not the one of an equilibrium types, but to make the best of the available information. It is thus impossible for Hayek that a figure such as the auctioneer exists, equalizing the offer and demand functions. As we know Hayek will always contest the possibility of an economic planning (Caldwell, 1997), yet defended by some economists in the general equilibrium theory paradigm.

We will however see that the focus upon the cognitive aspects of the coordination implies a new conception of the economic concepts of market and competition. We will not focus on the old conception that Hayek criticizes that we can find in Marshall, Walras or 
Chamberlain and stick to the Hayekian criticism of what he perceives as the standard view when he writes in the 1930's and 1940's. The main point here is not to characterize precisely the general equilibrium program (see Weintraub, 1983, 1985; Cot and Lallement, 2006), but to specify the conception of Hayek in order to compare it with the efficiency theorists.

\section{The Hayekian Conception of the Market and Competition}

The market is the device of coordination in Hayek's theory. Hayek will in his later work, especially Law, Legislation and Liberty, define this concept as a specific spontaneous order. The notion of order is not solely political but refers to all the situations of great complexity where it is impossible to assess the situation with universal laws (Hayek, 1955). The order exists in distinction with the organization, where the complexity - namely the fragmentation of information- is reducible enough to make planning possible, such as in a small business or a family. In comparison the order is the consequence of an irreducible complexity: nor the scientist neither the planner can produce a correct nomology of the situation. The definition of the market as an order is then particularly important, it ensues from the interactions of the individuals in a spontaneous, that is to say non-intentional, process. This process is the process of competition: 
Competition is thus, like experimentation in science, first and foremost a discovery procedure (...). Competition must be seen as a process in which people acquire and communicate knowledge; to treat it as if all this knowledge were available to anyone person at the outset is to make nonsense of it. (Hayek, 1979, p. 68).

The division of knowledge is the starting point of the theory and the competition is a procedure of research for the individuals. The market is not the place where an offer and a demand encounter but a processor of information since prices works as signals for the agents, giving them objective information for their actions (Bourdeau, 2014). Hayek takes seriously into account the social and cognitive aspects of the competition and the market, missing in the tradition of the general equilibrium, even if this paradigm is not fully developed when Hayek is writing his first article on the subject in 1937. This is why these theses are developed historically in a criticism of the general equilibrium theory by Hayek. Hayek has a vision of the competition and market in this theory as static. In this framework competition is a market structure where some conditions are fulfilled: atomicity, homogeneity, transparency, mobility of production factors and free access to the market. The individuals are price-takers and have the same information in virtue of transparency. Hayek may also have in mind the theory of Chamberlain, published in 1933, The theory of monopolistic competition, where the standards requirements for pure and perfect competition are not fulfilled. In this theory there are a lot of producers on the market but the products are heterogeneous, which implies some information 
asymmetry and a rupture with the atomicity condition. However, this distinction is not important in Hayek perspective because it is still too static. What Hayek criticizes is less the specificity of the five requirements for competition than its core conception as not well suited in order to take the dynamic substance of the economic process.

The classical conception of competition, the perfect competition, is thus replaced by a dynamic, a process of trade during which the information is shared and spread. The perfect competition, where every individual has all the information available is described as a way to dodge the real question because of its static characteristics. The perfect competition indeed takes for principle what is the result of a competitive process:

In other words, the description of competitive equilibrium does not even attempt to say that, if we find such and such conditions, such and such consequences will follow, but confines itself to defining conditions in which its conclusions are already implicitly contained and which may conceivably exist but of which it does not tell us how they can ever be brought about. (Hayek [ 1946] 1948, p. 94).

Or, in another passage:

Competition is essentially a process of the formation of opinion: by spreading information, it creates that unity and coherence of the economic system which we presuppose when we think of it as one market. It creates the views people have about what is best and cheapest, and it is because of it that people know at least as much about 
possibilities and opportunities as they in fact do. It is thus a process which involves a continuous change in the data and whose significance must therefore be completely missed by any theory which treats these data as constant. (Hayek [1946] 1948, p. 106).

Competition is then more of an epistemic process than a result. This epistemic dimension, in the sense that the agents in competition gather the information, is central because it changes the way we conceive competition itself. Competition is then seen as a process of rivalry. It is, not anymore, a market structure but a process between agents where information is shared and discovered and where everyone tries to adjust their anticipations in order to fulfil their projects. Competition is the general answer to the radical ignorance in which individuals are imprisoned. New information is discovered only because individuals are in competition, the market is then a competitive order. On this matter Hayek underlines then the entrepreneurial process of the competition (Kirzner, 1988). The two meanings of competition clearly appear here: competition as market structure is a situation when the market can equalize the offer and demand function, its meaning is the one of coordination; competition as rivalry in Hayek's work is not of the same kind, closer to the usual meaning of competition (Berthonnet, 2014). Thus, competition is defined as a tool in order to select good anticipations or even rationality. Rationality is consequently not a hypothesis but the result of competition, which selects the most efficient anticipations. This theoretical result is defended with an evolutionist approach in Hayek (1979), stating that competition results in the selection of rational 
behaviours and efficient rules, eliminating as a consequence the individuals that are less adapted:

The basic contention of theory is rather that competition will make it necessary for people to act rationally in order to maintain themselves. It is based not on the assumption that most or all the participants in the market process are rational, but, on the contrary, on the assumption that it will in general be through competition that a few relatively more rational individuals will make it necessary for the rest to emulate them in order to prevail. In a society in which rational behavior confers an advantage on the individual, rational methods will progressively be developed and be spread by imitation. (Hayek, 1979, 75).

This dynamic assures for Hayek a better allocation of resources, because the competition adapts to different situations: the price will thus incorporate the new information available and convey them. This consequence is not totally unfamiliar for whom knows the definition of efficiency proposed by Fama in his articles of 1965 (see section 2). The prices are therefore of central importance:

The sum of information reflected or precipitated in the prices is wholly the product of competition, or at least of the openness of the market to anyone who has relevant information about some source of demand or supply for the good in question. 
Competition operates as a discovery procedure not only by giving anyone who has the opportunity to exploit special circumstances the possibility to do so profitably, but also by conveying to the other parties the information that there is some such opportunity. It is by this conveying of information in coded form that the competitive efforts of the market game secure the utilization of widely dispersed knowledge. (Hayek, 1979, 117).

Prices are then a device of social coordination, incorporating the information of the entrepreuprenarial process in which individuals try to exploit "special circumstances" and opportunities, answering to the problem Hayek asked from a subjectivist point. The market is more of an information processor than the way to balance offer and demand for a good, making the social coordination possible. Hayek tends to restore the "invisible hand" of the market via the price system, which incorporates new information during the perpetual process of competition and can then convey a form of objective information. In a social order, which we distinguished before from an organization, the prices become one of the only ways to coordinate, because of the inherent complexity of the situation and the impossibility for an agent to centralize this information.

Thereby Hayek answers his question: how can an order exist without anyone organizing it? The market, as a spontaneous order, is a central element of the answer. It can transform the subjective information of individuals in an information objectivized by the prices. The dynamic aspect of the market, led by entrepreneurs who try to take advantage of 
opportunities is not ignored but this dynamic process is one of adaptation: the entrepreneurs show opportunities to the other who can imitate them and then stabilize the whole. This integration of the concept of information, that appears more and more often in Hayek's work, becoming preponderant in Law, Legislation and Liberty, and that he might take from cybernetics (Mirowski, 2002; Mirowski \& Nik-Khah, 2017), transforms then the concepts of market and competition.

Competition is a process of discovery and learning, and not a structure of market. The information is discovered through the process of competition and is not a hypothesis. The criticism of the general equilibrium model is built upon an epistemological view of the division of knowledge that leads to the redefinition of the core concepts of market and competition. One can see this elaboration in the articles of Hayek discussing the Socialist Calculation Debate (Hayek, 1948; Kirzner, 1988; Caldwell, 2004, 214-231). Thus, the Hayekian individual is an individual that constantly reacts to the stimuli of the price system and that produces anticipations according to the information he disposes. We will see that these views are not only hayekians.

Mirowski (2009a) attributes a dominant version of the concept of market to Hayek, who, according to him, transformed the ontology ${ }^{4}$ of the concept:

\footnotetext{
${ }^{4}$ The term "ontology" appears in Mirowski's article. However, we will not focus on the ontological dimension of the shift.
} 
Perhaps the dominant version at MPS (Mont-Pélerin Society) emanated from Hayek himself, wherein "the market" is posited to be an information processor more powerful than any human brain, but essentially patterned on brain/computation metaphors. (...). From this perspective, prices in an efficient market "contain all relevant information" and therefore cannot be predicted by mere mortals. In this version, the market always surpasses the state's ability to process information, and this constitutes the kernel of the argument for the necessary failure of socialism. (Mirowski \& Plewhe 2009, p. 435).

Here we can observe that the conception of the market which is said to be dominant in the Mont-Pélerin Society is the hayekian version of a market that contains all relevant information and thus is an information processor which is impossible to beat by a ruler or a mere mortal. We will see that this definition shares a lot with the definition of efficiency. In this conception the market differs from the Walrasian interpretation in different ways. If Hayek retains the idea of equilibrium from the walraso-paretian theory it is to explain the possibility of a tendency towards equilibrium (Caldwell, 1988; Arena, p. 1999). The pure market of the theory is criticized because it is highly tautological - two agents that know everything are in equilibrium only because we define equilibrium this way- and is begging the question of the discovery of the information itself. In his later work he abandons the notion of equilibrium for the one of order: the equilibrium supposes a static state where the information 
has been discovered already, while the conception of the competition and market of Hayek is highly dynamic:

We are accustomed to calling the order brought about by competition an equilibrium- $-\mathrm{a}$ none-too-felicitous expression, since a true equilibrium presupposes that the relevant facts have already been discovered and that the process of competition has thus come to an end. The concept of order, which I prefer to that of equilibrium, at least in discussions of economic policy, has the advantage of allowing us to speak meaningfully about the fact that order can be realized to a greater or lesser degree, and that order can also be preserved as things change. Whereas an equilibrium never really exists, one can nonetheless justifiably claim that the kind of order of which the "equilibrium" of theory represents a sort of ideal type is realized to a great extent. (Hayek, 1964, p. 12).

Hayek thereby transformed the concepts of competition and market from a questioning about the possibility of coordination between the individuals that have subjective information. These transformations are epistemological, regarding not only the concepts that Hayek uses and his position towards the general equilibrium tradition but also his broader representation of the social world. We showed that this representation is determined by his conception of the division of information. This starting point is the core hypothesis of his theory. This vision is encompassed in the fact that no one can beat the market because it incorporates all the relevant information. Hayek introduces consequently a fundamental symmetry between the observer, the planner, the scientist, the politician, and the observed. The knowledge is spread, 
shared, divided, and no one can surpass this essential division. Because of his epistemological position, defining information as subjective and heterogeneous there is no possibility of disengaged central view. This acknowledgment laid the foundations of the hayekian world where only unintentional processes such as evolution (Hayek, 1976) or competition can lead us. The result is that prices incorporate all relevant information and are the mean of coordination. This result is very close to the formulation of efficiency in finance as we already told. The next section will show that the developments that we can find in Working and Fama are following indeed the same questioning.

\section{When Efficiency Meets Hayek.}

In this second part, we are going to focus on the theory of informational efficiency developed in financial economics. A market is informational efficient if all information available about assets prices are integrated in current assets prices, which is indeed a formulation close to the one we extracted from Hayek. The informational efficiency represents a keystone of financial economics in many aspects. Historically speaking, the information efficiency has been one the key research program in the constitution of modern financial economics in the 1960s (Jovanovic, 2008). It still represents today the central framework in financial economics to describe the financial markets. Many subfields in financial economics have been dedicated to develop the implication of this hypothesis, and many other central contributions to financial 
economics claim a direct link with the informational efficiency (Vuillemey 2013). It should be noted then that information efficiency is not only a theory of information among others that we decided to compare to Hayek. Our focus on informational efficiency is also motivated by its importance on the historical constitution and his analytical centrality in the financial field.

Conversely to the hayekian theory of information, the informational efficiency has been developed by a set of heterogeneous researchers. The comparison with Hayek's theory requires then to avoid these heterogeneities to focus on the key ideas behind the information efficiency. We choose to present the contributions of Holbrook Working and Eugene Fama, assuming that the contributions of the formers are representative of the others contributions developing the informational efficiency at the same period. Our focus on Eugene Fama is obvious since his contributions are considered as the more systematic exposure of information efficiency. Holbrook Working, however, is known only by the specialists of the field as a pretheoretician of informational efficiency. However, the intuitions Working develops before Fama exposes with more clarity the epistemological breakthrough that we want to stress. We use him as a way to reveal the problematic that lay behind efficiency in order to intensify the comparison we propose with Hayek. We begin our account by presenting these intuitions, which consist mainly in introducing the role of expectations and the use of dispersal information in the determination of assets prices. We then display the more theoretical and systematic formulation of informational efficiency given by Fama. 


\section{Knowledge, Forecasting and Expectations:}

The issue about the use of knowledge in finance has been discussed openly by the first AngloSaxon researches on finance in the 1930s. The studies of Alfred Cowles questioning the forecasting skills of forecasters are an illustrative example (Cowles, 1933; Cowles \& Jones 1937; Cowles, 1944). Cowles shows that forecasts' forecasters were not better than a random strategy. Based on Cowles' studies, economists believe on the objective prediction of economic science, whereas traders were attacked for the unscientific character of their forecast (Dimand, 2009 \& Dimand \& Veloce, 2010). The question is then similar to Hayek's problem, in other words, the question of the centralization of information. In 1934, Working publishes a well-known article in which he notices the random character of assets prices fluctuations (Working, 1934). The knowledge issue rises naturally from this finding. Like Cowles, it questions the forecast of traders and thereby the knowledge used by traders to forecast. But Working insists also on the limited knowledge of economic theory, enable to explain such fluctuations. The innovative claim of Working is to put in the same line the issue about the knowledge of traders and the knowledge of economic theory. If random fluctuations question the forecasters' forecasting, why should it not question the economic science too? Really early, Working defends the intelligence of the practical men against the economists, for instance, in this wheat prices study:

Ask a number of intelligent business men of long experience with wheat prices to state the tendencies they believe to exist, and you will get much more general agreement with 
the propositions here stated that will be obtained from economic theorists. (Working,

1935, p. 425)

Working (1949) follows and reinforces the same trend by acknowledging that "perhaps the absence of recognized scientific significance of "traders' information reflects inadequacy of our perception rather than absence of real significance." (Working, 1949, p. 150). In short, maybe traders' expectations make sense: it reflects maybe the incapacity of economic theory to understand the expectations of traders and the information they use, namely not only scientific information but local and contingent information. Working suggests then that Cowles' finding should be reinterpreted:

Some years ago, Alfred Cowles made a critical study of the economic expectations recorded by professional stock-market forecasters. The main conclusion which emerged was that these expectations had characteristics substantially identical with those of random guesses. We shall see before we finish that such an observation is not necessarily evidence of poor forecasting. (Working, 1949a, pp. 151-152)

In order to show that, he makes a logical distinction between two kinds of expectations errors. First of all, errors can result from unpredictable factors, independent from the agents, what Working calls "necessary errors". It results then that the second kind of errors which may occur results from predictable factors, dependent on the agents, what Working calls “objectionable errors". In an "ideal market” (Working, 1949, pp. 160), expectations should be 
subject only to necessary errors, errors that result from an unpredictable event. Assets prices fluctuations of such a market will be entirely unpredictable:

Ideal market expectations would have taken full account of the information which permitted successful prediction of the price chance. [...] An interesting consequence of this proposition is that, given an ideal futures market in which market expectations exhibited only necessary error, it would be impossible for any professional forecaster to predict price changes successfully. (Working, 1949a, 160)

Working then links this finding to his own observations about the random character of financial fluctuations: "Changes which are completely unpredictable are, by definition, random changes" (Working 1949, 160).

The crucial point we want to stress here is that Working's contributions is not only theoretical, it is mainly a transformation of the relation between observer and observed about knowledge. From an overhanging position, the observer symmetrizes his cognitive capacity with the observed. Beyond the construction of a theory of expectations, he highlights the significance of the local and subjective knowledge of investor by suggesting that traders' expectations should be taken more seriously than it was:

Apparent imperfection of professional forecasting, therefore, may be evidence of perfection of the market. The failures of stock market forecasters, to which we referred earlier, reflect credit on the market. (Working, 1949, p. 160) 
In this respect, whereas the researchers of his time were looking for an objective model of forecasting, Working reverses the logic by modelling the subjective foreseeing of agents. It leads then to focus, not anymore on what kinds of knowledge is relevant, but on how agents use as best the knowledge, inaccessible to the theoretician:

Anticipating events requires special knowledge and special skills. While some traders seek to predict crop developments, others seek to predict changes in general business prospects. (Working, 1949, p. 194, we emphasize)

Noting that "the amount of pertinent information potentially available to traders in most modern market is far beyond what any one trader can both acquire and use to good effect", Working gives the intuition of the - hayekian like - division of knowledge:

Circumstance and inclination lead different traders to seek out and use different sorts of available information; and if at any time some sort of available and useful information is being generally neglected, someone is likely soon to discover that that neglect offers him a profitable field to exploit. In short, traders are forced and induced to engage in a sort of informal division of labor in their use of available information. (Working, 1958, p. 158, we emphasize)

Working do not formulate the informational efficiency explicitly though, but the fundamental intuitions were here and reveal explicitly his theory of knowledge. We can notice too that he uses the same argument as Hayek, who underlined the entrepreneurial process of the market. 
Here traders may be seen as the Hayekian's entrepreneurs. Here both arguments share the same structure. It is particularly interesting indeed that we find in Hayek's writing the same defence of traders' subjective knowledge:

or the arbitrageur who gains from local differences of commodity prices, are all performing eminently useful functions based on special knowledge of circumstances of the fleeting moment not know to others. It is a curious fact that this sort of knowledge should today be generally regarded with a kind of contempt, and that anyone who by such knowledge gains an advantage over somebody better equipped with theoretical or technical knowledge is thought to have acted almost disreputably (Hayek, 1948, pp. 8081, we emphasize).

We find then here the same emphasis on the necessity of local information and symmetry but also the same figure in order to make the market process work, that is to say the one of the entrepreneur/traders. However, if Working develops significantly the role of subjective knowledge, which is crystalized in a theory of expectations, we do not find in his writings a systematic representation of the market and the competition. This will be done by Eugene Fama. 


\section{Market as an Informational Processor}

Fama introduces the concept of "efficient market" in 1965 (Fama 1965a,b). In this definition, he draws a link between the information and the competition, a notion missing in Working's writing:

In an efficient market, competition among the many intelligent participants leads to a situation where, at any point in time, actual prices of individual securities already reflect the effects of information based both on events that have already occurred and on events which, as of now, the market expects to take place in the future. In other words, in an efficient market at any point in time the actual price of a security will be a good estimate of its intrinsic value. (Fama, 1965a, p. 76)

This first definition describes a financial market where the competition leads, first of all, to the integration of all information in the assets prices, and, secondly, to the equalization of assets prices to the intrinsic value. Although Fama consider the two aspects as synonym, he will give up this second aspect in his following writings to focus on the first part of the definition.

What appears already in this first definition is a particular conception of the competition: the competition is then a process which leads a set of subjective information to be centralized objectively in a system of prices. The market appears as a processor of information (Mirowski \& Nik-Khah, 2017), and prices as the result from this competition 
process. We find the same conception in Hayek's work where prices are the result of a social process of competition led by entrepreneurial actions of the individuals.

This conception of the market prices is particularly apparent in his review of empirical literature (1970). After he defines an efficient market as a market in which "prices always "fully reflect" available information" (Fama, 1970, 383), Fama distinguishes his famous three tests of informational efficiency: weak, semi-strong, and strong. The weak form tests if the market prices integrate all past information, the semi-strong form adds the current public information, and finally the strong form tests also the current private information (Fama, 1970, 388). Here information can refer to all the relevant data for an action. Beyond this classification of empirical tests, it appears as a classification of the capacity of the market to fill its role given by Fama, that is, to integrate in prices the dispersal information from the individuals. The similarity between hayekian and the informational efficiency is then multidimensional. Written in the same period, answering to a same issue about centralized knowledge, the two theories defend a new representation of the market as an informational processor.

Can we end the comparison so easily? But there are strong differences between the efficiency of Fama and the efficiency ${ }^{5}$ of Hayek's theory of prices. Until now, we passed over many analytical differences between the two approaches. The formulation of informational

\footnotetext{
${ }^{5}$ Our use of the term efficiency here for Hayek is anachronic and partly incorrect: Hayek never formulated a theory of informational efficiency. We use the same term here in order to facilitate the comparison.
} 
efficiency by Fama (1976a ; 1976b) will illustrate this issue. In (Fama 1976b) a market is efficient if and only if:

$$
f\left(P_{t} \mid \theta_{t-1}\right)=f_{m}\left(P_{t} \mid \theta_{t-1}^{m}\right)
$$

Where $P_{t}$ is the vector of price at time $t, \theta_{t-1}$ the set of information available at time $t-1$, $\theta_{t-1}^{m}$ is the set of information used by the market, $f\left(P_{t} \mid \theta_{t-1}\right)$ is the true density function implied by $\theta_{t-1}, f_{m}\left(P_{t} \mid \theta_{t-1}^{m}\right)$ is the market assessed density function for $\theta_{t-1}^{m}$ (see Fama 1976b, 143).

This formulation means that a market is efficient when the aggregate subjective information of individuals $f_{m}\left(P_{t} \mid \theta_{t-1}^{m}\right)$ equals to the $a$ priori objective information $f\left(P_{t} \mid \theta_{t-1}\right)$. In short, a market is efficient if the market expects rationally the prices. Fama specifies that by saying "the market" does something is just "convenient way of summarizing the decisions of individual investors and the way these decisions interact to determine prices" (Fama, 1976a, p. 135). This formulation avoids entirely the heterogeneity between individuals, a fundamental aspect of the hayekian theory we highlighted in the first part. Secondly the rationally that Fama use here is absolutely unfamiliar with the conceptions of Hayek. Indeed, Fama uses the word in relation with the rational expectations, while the expectations of Hayek are of a totally different sort. When Fama talks about market which "assesses probability distributions" implied by $f_{m}\left(P_{t} \mid \theta_{t-1}^{m}\right)$ he supposes two implicit assumptions: 
this can only be a completely accurate view of the world if all the individual participants in the market (a) have the same information and (b) agree on its implications for the joint distribution of future prices. (Fama, 1976a, p. 167)

Beyond the central aspect given to the information by each approach, the assumed cognitive abilities of individuals are however fundamentally different. It leads then Fama to fall under one of the main critics Hayek made to general equilibrium, that is, to dodge, by assuming a homogeneity, the real question of how a market composed by different individuals is ordered. He furthermore assumes (a) that the information is the same for everyone, which is, as Hayek said, a way to dodge the question. Can we then identify clearly the lineage between the two theories? The last section of our paper discusses this issue.

\section{Beyond Methodological Differences: The Problem of Comparisons}

In this section we propose to face what we call the problem of comparison. We will at first clarify the difficulties that we encounter when we want to propose a systematic comparison between Hayek, Fama and Working. Indeed, we showed that these authors shared common conceptions on information, markets and competition. But a cautious reading of the texts of these different authors also show very different orientations and propositions. The thesis of a lineage between Hayek and Fama, and more broadly the theory of informational efficiency, needs thus a more systematic demonstration. We will justify our interpretation with a 
distinction between methodology and epistemology, insisting on the fact that most differences lay in the realm of methodology. Finally, we will provide some examples in order to illustrate and defend our position.

\section{The Problem of Comparison}

We do not propose to go as far as David Laidler (1982) went with Lucas, Sargent and other economists of the new classical economics and say that Fama is a hayekian. Indeed, Hayek has been compared already with a lot of economists, and one must not confuse comparison with identification. Furthermore, neither Working nor Fama referred to Hayek as an inspiration to their work explicitly ${ }^{6}$. It is certain that there is a lot of differences between Hayek and, for example, Fama. First of all, the context in which Hayek writes is very different from the context that gives rise to financial economics and efficiency. Hayek reacts to historical and political problems, such as the World War, the rise of totalitarianism and, last but not least, the problem of economic planning. In order to understand his work, one has to investigate the crisis of the $\mathrm{XX}^{\mathrm{th}}$ century. He is not strictly speaking an economist after the second World War, but belongs to social sciences departments and focus on much larger problems of political philosophy, eager to spread a revigorated liberalism with the Mont-

\footnotetext{
${ }^{6}$ If we except the fact that Fama describes himself in an interview in the New York Times in 2013, october 26, as "an extreme libertarian" and as a reader of Hayek's Road to Serfdom. Some chronological conjectures can be proposed in order to link Hayek with Working too, notably the fact that the 1949 article of Working, written after the 1944 article of Hayek which had a lot of success, seems to borrow some conceptions to the hayekian theory.
} 
Pélerin Society (Mirowski \& Plewhe, 2009; Audier, 2012; Burgin, 2012). Working and Fama did not join the Mont-Pélerin Society, neither did they frankly and openly took position for liberalism and political issue. Their writings contribute to the constitution of a new subfield of economics, the modern financial economics. Thereby, they are concerned by scientific issues, mainly, convincing economics and practitioners of the relevancy of new object for economic analysis, the financial market (Fourcade et Khurana 2013, 2017; Jovanovic 2008).

Consequently, and secondly, the scope of the hayekian's theory is much broader than the scope of Fama's work: Hayek is interested in philosophical problems of social coordination, to elaborate a theory of social norms and their evolution, and to develop a theory of human conduct, many problems that do not appear in the work of Fama. There are some differences in terms of problematic: the "Hayek problem" (Van Zjip, 1990) is the very general one of inter-individual coordination, while the problems that give rise to the financial economics are related to the more specific issue about the performances of the investors.

Finally, their methodologies distinguish themselves considerably. The assumptions on the individuals are clearly different, something currently highlighted when Hayek is compared to others economic thoughts. For instance, Audier (2013) argued that the representation of the individuals in Hayek and in the Chicago School are radically different, the first developing a theory of rules-following, the second holding on homoeconomicus. The same can be said for the concept of anticipations that Hayek, Working and Fama use. For Hayek the anticipations are not rational, as Butos (1997) showed with a precise reading of Hayek's book Sensory 
order, but local, related to the limited information the agents possess and consequently heterogenous, closer to a tacit disposition than an intentional view while in Fama's work the anticipations are homogenous between individuals and are explicit. It is assured consequently that Hayek and Fama do not share the same representation of the agents, Hayek being more interested in a general description of human action, while Working and Fama follow the modeling trends after the World War II.

Methodology and epistemology

How can we then justify our thesis of a theoretical lineage between Hayek and the corpus in financial economics? We characterized the similarities and the differences highlighted as respectively epistemological and methodological. The term epistemology here is not related to the theory of science the authors defend, their methodology or concepts, or their explicit problematic, but to the core concepts or their theories. The history of financial economics encounters the same problem of the division of knowledge than Hayek and develops the same answers: subjectivism for the knowledge, symmetry between the observed and the observer with the impossibility to centralize information, which gives birth to the same modification, beyond methodological differences, in the concept of market and competition. We called this epistemology in order to underline the fact that the authors, in different levels, share the same vision of information, conveyed by the prices through process 
of competition that differentiate itself from the neoclassical view of market and competition, and sometimes perform hybridization between the neoclassical views and those transformed concepts (Berthonnet, 2014). This same vision relies on the same philosophical hypothesis. We ought then to distinguish between epistemology, relative to the social philosophy and world representation of the authors, and methodology, relative to the scientific way the authors embody these theses.

Many writings of famous methodologists or philosophers of economics define methodology in a various way. The pioneer work is the distinction between Methodology and methodology by Mccloskey (1986). Methodology refers to the philosophy of science the authors explicitly claim, while methodology refers to the day-to-day professional activities. Since then many definitions have been provided. For Rosenberg $(1992,10)$ for example a methodology is a set of rules that ensue from a theory, that is to say the way we can operationalize a theory in practice. Blaug (1992, xii) defines methodology differently:" methodology is that branch of economics where we examine the ways in which economists justify their theories and the reasons they offer for preferring one theory over another".

In the same fashion, epistemology usually refers to the philosophy of science, and especially to the criterion that are used by authors such as Popper, Kuhn, Lakatos or Feyerabend for example in order to distinguish science and pseudo-science. Authors can then be verificationnists, falsificationnists, realists or antirealists, instrumentalists etc. 
Broadly most definition of methodology and epistemology are meta-theoretical, in other words, related to an external appraisal of the methodology of sciences authors practice or claim, or to the scientific criterion they accept. It is then a normative approach. We do not aim to take part in these questions of definitions. Our distinction is far more down to earth and less normative. We call epistemology the core hypothesis of the theories, that is to say the theoretical positions that support the whole theory. An ambiguity is hidden in the fact that what we identify as the core hypothesis in Hayek and Fama are hypothesis regarding the knowledge and its division, namely regarding epistemology in the etymological meaning of theory of knowledge. We can then say that the Epistemology in Hayek's and Fama's work is about the epistemology of the individuals, based on underlying hypothesis about social coordination explicitly formulated in Hayek's work. Methodology is then defined as the way the authors operationalized their theory in the field of scientific production. We borrow this mode of thinking to Lakatos (1970). Nevertheless, we do not use this distinction as a normative distinction in order to assess programs of research.

It is certain that this distinction cannot be a sharp one: where does methodology ends and where does epistemology begin? These are questions that cannot be resolved in an abstract way, but shall be answered in situ, confronting specific cases (Kincaid \& Ross, 2009).

Epistemology is then related to the fundamental view of knowledge, which is for Hayek, and as we tried to defend, for Fama, divided, not centralized and heterogenous. Two 
authors can share the same epistemology (considering for example that knowledge is divided, local and that there can be no centralization of it) and differ on methodological matters (on the definition of anticipations, the models they use, or the representation of the cognitive abilities of the agents). That being said methodological differences can be really important and decisive differences and give birth to radically different theories. Hacking (1983) shows for example that the bottom up approach founded upon the practices of the day-to-day scientist was crucial in order to understand the long run diversification of theories. Our thesis is that the differences between Hayek and the corpus we studied in the theory of efficiency, especially Fama, are mostly methodological. For example, the use of rational anticipations by Fama, that contrast with the Hayekian vision of individuals, is explicitly for Fama a mean to study the market itself. Thus, the differences in terms of methodology are highlighted by a common background, which is composed of common epistemological problems. As Hacking $(1983,5)$ shows with Popper and Carnap the differences appear sometimes greater than they are when there is a common ground upon which they become commensurable.

\section{A Same Epistemology: Information and Symmetry}

The issue about information can be seen as the keystone of the Hayekian and informational

efficiency: the two theoretical approaches start from the highlight of the difficulty to centralize the knowledge (by governmental or scientific entities). This difficulty leads Hayek 
as well as Working and Fama to stress the role of local and subjective knowledge, knowledge which cannot be fully taken into account by sciences. We already see that both Hayek and Working, before any theoretical analysis, try first of all to revaluate the subjective knowledge of specialized agents, knowledge intrinsically personal and therefore, intangible for economic sciences.

The notion of information appears as the objective description of this unattainable knowledge, that is, an objective description of an unopened black box. The concept remains then not well defined. In the Hayekian and informational efficiency theories, there are not attempts to describe with precision the content of the information used by agents ${ }^{7}$. The notion of information is only described by its finality: agents use information they need to achieve an economic action. They had the correct information if this action is actually achieved. The theory does not and cannot discuss the content of the local and subjective information used by agents since it is defined as not possible to centralize by a theoretician.

There exist though some differences. For instance, in Fama (1970) "prices always "fully reflect" available information". This conception of information borrows to the conception of the equilibrium analysis of free information. Hayek insists on the dynamic

\footnotetext{
${ }^{7}$ Hayek provides some examples on this subject, especially in his texts on the Debate on the possibility of economic calculation under socialism. For example, Hayek $(1948,154)$ : « The information which the. central planning authority would need would also have to include a complete description of all the relevant technical properties of everyone of these goods, including costs of movement to any other place where it might possibly be used with greater advantage, cost of eventual repair or changes, etc. »
} 
process of discovery of information through competition and entrepreneurship. The position of Fama is then the result of the hayekian process of competition.

It is then true to say that Hayek opened an era (Hirschleifer, 1973) which can be called the era of information in economics. Another way to stress this epistemological similarity is the introduction by both approaches of symmetry between the observer and the observed. This symmetry is implied both in the work of Hayek and in the works of Fama and Working, as a consequence of their position on information. Hayek introduces symmetry (Sent, 1998) between the observer and the observed, because of the impossibility to centralize all the information, as we showed above. The impossibility to centralize deprives the scientist, or the ruler, of his prominent situation. We have seen that the problem gives rise to the questioning, by Working, of the scientific knowledge. In a perfect market all the information is integrated into the prices, which makes the prediction impossible for an individual, even for the most talented scientist.

The theoretical starting point of the authors is thus the same since they share a common understanding of the notion of information. This common understanding reveals a common representation of the interaction between individuals and then an answer to the problem of coordination.

\section{Market and Competition}


By stressing and systemizing the issue about information, both theories offer a new conception of what is the market and what role it fulfils. The market described by both theories fills a new role: to centralize this subjective information in a price system. The market plays the role that was before the one of the governments. Market usual main role is to coordinate the supply and the demand; it is from now on to coordinate the agents in their research of information. The shift is noticeable: the question is not only the one of the allocation of resources but of social coordination. It takes it ground in the philosophical question of social order. Hayek explicitly formulates this:

The mere fact that there is one price for any commodity-or rather that local prices are connected in a manner determined by the cost of transport, etc.-brings about the solution which (it is just conceptually possible) might have been arrived at by one single mind possessing all the information which is in fact dispersed among all the people involved in the process. (Hayek 1948, 86)

Hayek described this as a "marvel" (Hayek, 1948, 87): the functioning of the market, with prices coordinating the individuals and their actions, takes the role of the central institution of our society. Hayek explicitly adds a second role to the market, which combines with the more traditional vision of the market. This Hayekian conception of the market has been linked to informational efficiency by Grossmann and Stiglitz (1976, 249): 
Still a third important and related observation is that prices, in our model, are serving two functions: not only are they being used to clear markets in the conventional way, but they convey information

This combination is noticeable in Fama's thesis, which supposed that every individual has access to the same information: prices reflect all the available information that the individual has, but it is also a conveyor of information itself. ${ }^{8}$ In the same vein, the role of the competition changes. Competition appears as an impersonal mechanism that selects and discover relevant information, or more specifically, selects the relevant economic action using relevantly the current information. Competition is therefore a dynamic process, a process that leads information to be discovered, shared, and spread. In this perspective we shall not underestimate the importance of the entrepreneurial action of the individual, highlighted by Hayek as well as by Working. Their role is to use unseen opportunities and then discover new information. Of course, it does not mean that this role for competition has been invented fully by informational efficiency and Hayekian theory. In the history of informational efficiency, it is particularly usual for instance to find these intuitions in many others and preliminary works, of the period or even before. ${ }^{9}$ However, informational efficiency and Hayekian theory appear as a systemizing analysis of this market conception. It does not mean neither that the idea that market coordinates the supply and demand disappears entirely from these frameworks. It is

\footnotetext{
${ }^{8}$ We set aside the fact that these two conceptions might not be logically compatible since we focus upon the comparison of the theories and not their validity.

${ }^{9}$ See for instance the discussion of the Kendall's conference (1953). See also (Walter, 1996; Jovanovic 2008) for the early contributions which formulates intuitively the informal efficiency.
} 
for instance easy to separate agent seeking for information between suppliers and demanders, but these concepts become minor aspects relatively to the main problem of the coordination of dispersal information. ${ }^{10}$ We let the study of the hybridization between the two forms of market and competition open for further investigations.

\section{Two Theories of Prices}

Because the authors share a common ground on the division of information throughout society and a similar definition of information, we can formulate a theory of efficiency in Hayek's work. As we have seen the first formulation of Fama (1965a) efficiency as the fact that prices reflect all available information. This intuition is developed by Hayek in 1944, especially in "The use of Knowledge in Society", as many authors noticed (Vivès, 2008). The price system is understood as a mechanism for communicating information (Hayek, 1948, 86), information that is made public by competition:

Fundamentally, in a system in which the knowledge of the relevant facts is dispersed among many people, prices can act to co-ordinate the separate actions of different people in the same way as subjective values help the individual to co-ordinate the parts of his plan. It is worth

\footnotetext{
${ }^{10}$ Working himself (1958) has a hybrid status and mixes his analysis of information with the classic concepts of supply and demand.
} 
contemplating for a moment a very simple and commonplace instance of the action of the price system to see what precisely it accomplishes. Assume that somewhere in the world a new opportunity for the use of some raw material, say, tin, has arisen, or that one of the sources of supply of tin has been eliminated. It does not matter for our purpose-and it is significant that it does not matter-which of these two causes has made, tin more scarce. All that the users of tin need to know is that some of the tin they used to consume is now more profitably employed elsewhere and that, in consequence, they must economize tin. There is no need for the great majority of them even to know where the more urgent need has arisen, or in favor of what other needs they ought to husband the supply. If only some of them know directly of the new demand, and switch resources over to it, and if the people who are aware of the new gap thus created in turn fill it from still other sources, the effect will rapidly spread throughout the whole economic system and influence not only all the uses of tin but also those of its substitutes and the substitutes of these substitutes, the supply of all the things made of tin, and their substitutes, and so on; and all his without the great majority of those instrumental in bringing about these substitutions knowing anything at all about the original cause of these changes. (Hayek, (1944) 1948, 85-86).

The prices in Hayek's terms allow an economy of knowledge: we don't have to know everything, since the prices reflects the information and are enough to take our decisions. The 
theory of Hayek states that prices will reflects all the available information and that a free market, assuming that there is no rigidity that would make it work less efficiently ${ }^{11}$.

We can see that there is a difference with Fama, for whom there is an intrinsic value (Fama, 1965a, 76) and then the prices reflect fully all the information (Fama, 1970). We already noticed that the Hayekian perspective was processual, that is to say that the adjustments are not automatic but are performed by competition, understood as a discovery of information process. If we find the same idea in the theories of prices of the authors, we can say that Fama defend the market efficiency, that is to say that all the relevant data are incorporated instantaneously in the prices, while Hayek defends a weaker version, we may call it a conception of the market as powerful, since the market is said to integrate information better than any individual or institution separately.

We cannot then say that Hayek developed fully a theory of prices as being efficient, but this difference doesn't break the lineage between the authors since most of Fama's work is filled with methodological assumptions in order to operationalize his theory. We will argue that under the real methodological differences between the authors, that we are going to discuss now, there is a common understanding of how market, competition and prices act.

\section{Methodological Differences}

\footnotetext{
${ }^{11}$ The term "efficient" appears in Hayek's work, in order to say that the free market is more efficient than the socialist society. The price system is then defined as "efficient" by Hayek, see Hayek $(1948,87)$.
} 
We already showcased some differences in the context of their writings and the scope of the two respective approaches. These differences are crucial since they imply significant analytical differences. Hayek is reacting directly to the political philosophy behind the general equilibrium problem, his answer shares the same level of generality: a description of the economic system that he tries to spread outside the scientific field. On the other side, Working is concerned by finding a consistent explanation of an unstudied object. The representation of the market he draws is secondary relatively to the scientific issue of a new field. Even Fama, who draws a more systematic representation of how are functioning the financial markets, is first of all concerned by the testability of his theory, an empirical research in which he will contributes actively. Furthermore, following the trends of North American economic researches, Fama insists on the necessity to build rigorous, that is a formal, model. From his first articles on informational efficiency (1965a,b), his literal model become formal (1970; 1976a,b). The information becomes a given mathematical set, and the representations of agents about future become a given law of distribution. The fundamental dynamic aspect of Hayek or Fama (1965a,b), implied by the crucial heterogeneity between agents, disappears. In the same vein, Fama's efficiency $(1965 a, 76)$ assumes that information is "almost freely available" what has been seen as contradictory with the hayekian theory in which costly information is central. If the information is freely available and reflected in price, the incentives for a competition on information disappear (see Stiglitz \& Grossman 1980, 404405). Hayek indeed, as soon as 1935 , in an article on the socialist calculation debate called 
"Socialist Calculation: The Nature and History of the Problem", noticed that what made planning impossible was the fact that information was not free but costly at an individual level. $^{12}$

Let's reused the example of Fama (1976) to show that these strong differences belong to methodology. Fama adopts a formal formulation which contrasts de facto with (Fama, 1976a,b) the hayekian's one. Specifically, by assuming a probability law for the "market", Fama avoids all the differences in the individuals' opinions. This assumption is a methodological one in the sense we give to this notion. It is a way to operationalize the theory, that is, to represent a testable formulation of the informational efficiency. The test cannot focus on unobservable individual's opinions, but only an aggregative observable set of information (such as past prices, public information, private information). Fama does not defend these assumptions as ontological features of the world, he actually has in mind individuals with heterogeneous opinions:

Strictly speaking, this implies that investors have monolithic opinions about available information and act single-mindedly to ensure that their assessments are properly reflected in current prices. What we really have in mind, however, is a market where

\footnotetext{
12 " The economic problem arises, therefore, as soon as different purposes compete for the available resources. The, criterion of its presence is that costs have to be taken into account. Cost here, as anywhere, means nothing but the advantages to be derived from the use of given resources in other directions. Whether this is simply the use of part of the possible working day for recreation, or the use of material resources in an alternative line of production, makes little difference. It is clear that decisions of this sort will have to be made in any conceivable kind of economic system, wherever one has to choose between alternative employments of given resources. " (Hayek, (1935) 1948, 123).
} 
there is indeed disagreement among traders but where the force of common judgments is sufficient to produce an orderly adjustment of prices to new information. (Fama, 1976a, 168, we emphasize)

Fama investigates the testability of an informational efficient market, the finality of the dynamic processes describes by Hayek. The differences in terms of scope then implies a difference in terms of methodologies: Fama wants to test his model and is then forced to use simplifications and a static viewpoint whereas Hayek aims at describing an unending process. In this regard, if informational efficiency has a hybrid status it respects the Hayekian view of market as informational processors but it stands out from the former by focusing, as the general equilibrium, the result and not the process itself (Stiglitz \& Grossman 1980). ${ }^{13}$ A common theory of knowledge remains, which seeks to describe a market in which subjective information of individuals is ordered in an objective system of price. Individuals are thought as entrepreneurs with special knowledge. Both theories develop price efficiency criteria characterized fundamentally by the epistemic superiority of the market on any individuals or group of individuals. Maybe the closest, and in the same time the more important, aspect brought by these theories, is a new way of thinking the determination of prices.

\footnotetext{
${ }^{13}$ The closeness of informational efficiency with the language of general equilibrium has played a key role in the emergence and the legitimation of financial economics as a scientific field (Jovanovic 2008).
} 


\section{Conclusion:}

The first result of our analysis is to deny the claim that informational efficiency is Hayekian and conversely. The methods, the contexts and the scopes are too different, beyond the fact that neither Working nor Fama explicitly refer to Hayek as a source of theoretical inspiration. However, stressing fundamental differences between both approaches does not imply that there are perfectly orthogonal. Considering the many aspects of their analytical proximity; the problem of centralized knowledge, the importance of subjective and local information that systemizing the representation of a market as an informational processor, it seems difficult to not bring closer both approaches.

We used in order to encapsulate this idea the expression of epistemological similarity. The similarity is labelled as epistemological in distinction with methodology. The literature underlying the differences between Hayek and other thinkers is acknowledged but, because of its main focus on methodological aspects, not considerate relevant on the epistemological level that is our main concern. Indeed, we showed that beyond effective differences the authors shared a common representation on the division of information and the conception of market and competition which derives from it. These results underline the importance of the mutation introduced by Hayek in economics, as proposed by authors such as Mirowski (2007, 2009a,b) or Cahill \& Konings (2017) for example. 
The epistemological similarity we stress raises also historical issues. If we aim at comparing analytically two set of a priori independent corpuses, it is clear that the proximity between the two approaches questions the potential inter-influence between the authors. If the influence of Hayek has been investigated, it remains a mystery how the concept of information appears so spontaneously and becomes central in financial economics. Even if any direct link can be built between Hayekian theory and informational efficiency, it raises a more important issue about how these two apparently independent theoretical innovations, written nearly at the same period, share so much. In other words, they are maybe two different ends of a same set of causes, and therefore, they are just reflecting a more general and deeper change at this period. This brings us back to the question of the possible Weltanschauung shared by the authors of the period, that some scholars labelled neoliberalism (Mirowski \& Plewhe, 2009; Burgin, 2012; Cahill \& Konings, 2017). 


\section{Bibliography:}

Audier, S.2013. Les paradigmes du Néolibéralisme, Cahiers philosophiques, 133(2), 21-40.

Arena, R., 1999, Hayek et l'équilibre économique, une autre interprétation. Revue d'économie politique, 109(6), 847-856.

Bachelier, Louis. 1900. Théorie de La Spéculation, Paris : Gauthier-Villars.

Berthonnet, Irène. 2014, De l'efficacité à la concurrence : Histoire d'une synthèse entre économie néoclassique et néolibéralisme. Thèse, Université de Lille 1.

Birner, J. 2006. La place de Sensory Order dans l'œuvre de F.A.Hayek, Cahiers d'économie Politique / Papers in Political Economy, 51(2), 109-138.

Blaug, M. 1992. The Methodology of Economics. Cambridge: Cambridge University Press.

Bourdeau, M. 2014. L'idée d'ordre spontané ou le monde selon Hayek, Archives de Philosophie, 77(4), 663-687.

Burgin, A. 2012, The Great Persuasion, Cambridge: Harvard University Press.

Butos, W. 1985, Hayek and General Equilibrium Analysis, Southern Economic Journal, 52(2), 332-343. 
Butos. W. 1997, Hayek and Rational Expectations in W. Keizer, B. Tieben \& R. van Zijp, Routledge(eds), Austrian Economics in Debate, London: Routledge, 220-242.

Cahill, D. and Konings, M. 2017. Neoliberalism. Cambridge: Polity Press.

Caldwell, B. 1984, Disentangling Hayek, Hutchison and Popper on the Methodology of Economics, Greensboro: University of North Carolina, Manuscrit.

Caldwell, B. 1988, Hayek Transformation. History of Political Economy, 20 (4): 513-541.

Caldwell, B. 1997, Hayek and socialism. Journal of Economic Litterature, 35 (4): 18561890.

Caldwell, B. 2004, Hayek's Challenge: An Intellectual Biography of F.A. Hayek, Chicago:

University of Chicago Press.

Caré, S. 2016. La dérive des continents néolibéraux : essai de typologiedynamique. Revue de philosophieéconomique, 7(1), 21-55.

Cot, A. and Lallement, J. 2006. 1859-1959 : de Walras à Debreu, un siècle d'équilibre général. Revue économique, 57(3): 377-388.

Cowles, A. 1933. Can Stock Market Forecasters Forecasts. Econometrica 1: 309-24.

Cowles, A. 1944. Stock Market Forecasting. Econometrica 12(3): 206-14. 
Cowles, A., and Herbert Jones. 1937. Some a Posteriori Probabilities in Stock Market Action." Econometrica 5: 289-94.

Colander C. \& Guthrie, S. 1980. Great expectations, what the dickens do "rational expectations" mean?; Journal of Post-Keynesian Economics 3(2), 219-334.

Dardot, P. and Laval, C. 2009, La nouvelle raison du monde, Paris : La découverte.

Dimand, R. and Veloce, W. 2010. Alfred Cowles and Robert Rhea on the Predictability of Stock Prices. The Journal of Business Inquiry 9(1)

Dimand, R. 2009. The Cowles Commission and Foundation on the Functioning of Financial Markets from Irving Fisher and Alfred Cowles to Harry Markowitz and James Tobin. Revue d'Histoire des Sciences Humaines, 20(1):79-100.

Dostaler, G. 2001. Le libéralisme de Hayek, Paris : La découverte.

Duménil, G. Lévy, D. 2014, La grande bifurcation : en finir avec le néolibéralisme, Paris : La Découverte.

Fama, E. F. 1965. The Behavior of Stock-Market Prices. The journal of Business, 38(1), 34105.

Fama, E. 1965. Random Walks in Stock Market Prices. Selected Papers of the Graduate School of Business, University of Chicago, Reprinted in the Financial Analysts 
Journal (September - October 1965), The Analysts Journal, London (1966), The Institutional Investor, 1968., October, 55-59.

Fama, E. 1970. Efficient Capital Markets: A Review of Theory and Empirical Work, The Journal of Finance 25(2): 383-417.

Fama, E. 1976a. Foundations of Finance: Portfolio Decisions and Securities Prices. New York: Basic Books.

Fama, E. 1976b. Efficient Capital Markets: Reply. The Journal of Finance 31(1): 143-145.

Fourcarde-Gourinchas, M. and Babb, S. 2002. The rebirth of the liberal creed: paths to neoliberalism in four countries, American Journal of Sociology, 108(3): 533-579.

Fourcade, M. and Rakesh K. 2013. "From Social Control to Financial Economics.", Theory and Society, 42(2), 121-159.

Fourcade, M. and Rakesh K. 2017. The Social Trajectory of a Finance Professor and the Common Sense of Capital. History of Political Economy 49(2): 347-81.

Fox, J. 2011. The Myth of the Rational Market: A History of Risk, Reward, and Delusion on Wall Street. Reprint edition. New York: HarperBusiness.

Grossman, J. and Stiglitz, J.E. 1976. Information and Competitive Price System. The American Economic Review, 66(2): 246- 253. 
Hacking, I. 1983, Representing and Intervening, Cambridge: Cambridge University Press.

Hayek, F, 1948, Individualism and economic order, Chicago: Chicago University Press.

Hayek, F.1952. Sensory order, Chicago: Chicago University press.

Hayek, F. 1955. The Counter-Revolution of Science, Glencoe: Free Press.

Hayek, F. 1964. "Competition as a discovery Procedure.” The Quaterly Journal of Austrian Economics, 5(3): 9-23.

Hayek, F. 1973. Law, Legislation and Liberty, I. London: Routledge.

Hayek, F. 1976. Law, Legislation and Liberty, II. London: Routledge.

Hayek, F. 1979. Law, Legislation and Liberty, III. London: Routledge.

Hirshleifer, J. 1973. Where are we in the theory of information? The American Economic Review, 63(2): 31-39.

Hutchison, T.1981, The Politics and Philosophy of Economics: Marxians, Keynesians and Austrians. New York: New York University Press.

Hoover, K. 1988. The New Classical Macroeconomics. Oxford: Basic Blackwell.

Jovanovic, F. (2008). The construction of the canonical history of financial economics. History of Political Economy 40(2), 213-242. 
Kantor, B. 1979. Rational Expectations and Economic Thought, Journal of Economic Literature, 17(4), 1422-1441.

Kendall, M. 1953. The Analys of Economic Time-Series-Part I: Prices. Journal of the Statistical Royal Society. Serie A (General) 116(1): 11-34.

Kincaid, H. and Ross, D. 2009. Introduction to the Oxford Handbook of Philosophy of Economics. Oxford: Oxford University Press.

Kirzner, I. 1988. The Economic Calculation Debate: Lessons for Austrians. Review of Austrian Economics 2(1): 1-18.

Konings, M. 2018. Capital and Time: For a New Critique of Neoliberal Reason. Stanford: Stanford University Press.

Krippner, R. 2005. The Financialization of the American Economy, Socio-Economic Review, 3(2): 173-208.

Laidler, D. 1982, Monetarist Perspectives, Cambridge: Harvard University Press.

Lakatos, I. 1970. Falsification and the Methodology of Scientific Reasearch Programmes, Criticism and the Growth of Knowledge, ed. Lakatos and Musgrave, 91-196.

Lave R., Mirowkski, P. \& Randalls, S. 2010, STS and neoliberal science, Social studies of science, 40(5), 659-675. 
Lucas, R. 1983, Methods and Problems in Business Cycle Theory, Journal of Money, Credit and Banking, 12(4), 696-715.

McCloskey, D. 1986. The Rhetoric of Economics. Madison: University of Wisconsin.

Mirowski, P. 2002. Machine Dreams, Cambridge: Cambridge University Press.

Mirowski, P. 2007. "Naturalizing the market on the road to revisionism: Bruce Caldwell's Hayek's challenge and the challenge of Hayek interpretation", Journal of Institutional Economics, 3(3), 351-372.

Mirowski, P. Plewhe, D. 2009a, The road to Mont-Pélerin, Cambridge: Harvard University Press.

Mirowki, P. 2009b, Why there is no such thing as Economics of knowledge, in The Oxford Handbook of Philosophy of Economics, ed. Ross, D. and Kincaid, H., Oxford, Oxford University Press.

Mirowski, P. Nik-Khah, E. 2017. The Knowledge We Have Lost in Information. Oxford : Oxford University Press.

Mougeot, C. 2009, Théorie autrichienne du cycle et théorie des cycles d'équilibre, Revue française d'économie, 24(4), 67-92. 
Picavet, E. 2013, L'approche économique, le rejet du néolibéralisme et l'Europe, Cahiers philosophiques 133(2), 65-78.

Rosenberg, A. 1992. Economics- Mathematical Politics or Science of Diminishing Returns? Chicago: University of Chicago Press.

Vivès, X. 2008, Information and learning in markets, Princeton: Princeton University Press.

Vives, X. 2014. On The Possibility of Informationally Efficient Markets. Journal of the European Economic Association, 12(5): 1200-1239.

Vuillemey, G. (2013). Sur le statut épistémologique de l'hypothèse d'efficience des marchés. Revue de philosophie économique 14(2), 93-118.

Walter, C. 1996. Une histoire du concept d'efficience sur les marchés financiers. Annales. Histoire, Sciences Sociales 51(4) : 873-905.

Walter, C. 2013. Le modèle de marché au hasard en finance. Paris : Économica.

Weintraub, E.R. 1983. On the existence of a competitive equilibrium: 1930-1954. Journal of Economic Literature, 21(2): 1-39.

Weintraub, E.R. 1985. General Equilibrium Analysis: Studies in Appraisal. Cambridge: Cambridge University Press. 
Working, H. 1934. "A Random-Difference Series for Use in the Analysis of Time Series." Journal of the American Statistical Association 29(185): 11-24.

Working, H. 1949. "The Investigation of Economic Expectations." The American Economic Review 39(3): 150-66.

Working, H. 1958. A theory of anticipatory prices. The American Economic Review, 48(2), 188-199.

Zijp, R. 1990, « Why Lucas is not Hayekian », Research Memorandum Series, n³3,

Tinbergen Institute. 